\title{
MetAZOAN PARAsites OF THE JACK MACKEREL TRACHURUS MURPHYI (Teleostel, Carangidae) in a latitudinal gradient from South America (Chile and Peru)
}

\author{
OLIVA M.E.*
}

\section{Summary :}

The metazoa parasite fauna of the jack mackerel Trachurus murphyi Nichols 1920, obtained from seven ports from a latitudinal gradient of more than $30^{\circ}$ (From Paita Peru: $05^{\circ} 10^{\prime} \mathrm{S}$ to Talcahuano, Chile $36^{\circ} 40^{\prime} \mathrm{S}$ ) was quantitatively described. 21 species of metazoan parasites were recorded (Monogenea 4, Digenea 3, Cestoda 5, Acanthocephala 2, Nematoda 4, Copepoda 2, Isopoda 1). Only four parasites (Lernanthropus trachuri, Ceratothoa gaudichaudii, Corynosoma australis, Anisakis simplex) were common to the seven ports. Only twelve species reach prevalence over $5 \%$ in at least one port. Main characteristic of the parasite fauna is the sparse of adult helminthes, specifically digenean and the dominance of larval forms, at both qualitative and quantitative levels. There are not evidence of changes in the parasite community along a latitudinal gradient, but at least Anisakis simplex (larvae) shows a trend in both, prevalence and mean intensity, increasing from north to south.

KEY WORDS : metazoan parasites, jack mackerel, Trachurus murphyi, latitudinal gradient, Chile, Peru.

\section{INTRODUCTION}

T The knowledge of the parasite fauna of marine fishes from Chile and Peru at communitary levels, has increased in the last years (see for instance Gonzalez \& Acuña, 1998 for Chile and Oliva \& Luque, 1998 for Peru). Studies have focused, primarily, on marine fishes of economic importance, such as hakes (Merluccius spp.) and jack mackerel (Trachurus murphyi). The jack mackerel Trachurus murphyi is the most important source for fish meal and the last available fishing statistics (SERNAPESCA, 1997) show that landing reached more than 2,900,000 metrics ton for 1997, in Chile. In spite of the economic importance of this fish, only two papers (George-Nascimento \& Arancibia, 1992; Oliva, 1994) dealing with quantitative studies about the metazoan parasitic com-

* Instituto de Investigaciones Oceanológicas, Facultad de Recursos del Mar, Universidad de Antofagasta, Antofagasta, Chile.

Phone: 56-55-637404 - Fax: 56-55-637804.

e-mail: moliva@uantof.cl
Résumé : MÉTAZOAIRES PARASITES DU CHINCHARD TRACHURUS MURPHYI (Teleostei, Carangidae) Selon un gradient latitudinal EN AMÉrique du Sud (Chili et Pérou)

La faune des métazoaires parasites du chinchard Trachurus murphyi, Nichols 1920, étudiée dans sept ports le long d'un gradient latitudinal de plus de $30^{\circ}$, entre Paita (Pérou, $05^{\circ} 10^{\prime} \mathrm{S}$ ) et Talcahuano (Chili, $36^{\circ} 40^{\prime} \mathrm{S}$ ) est décrite de façon quantitative. 21 espèces de métazoaires parasites sont enregistrées

4 Monogenea, 3 Digenea, 5 Cestoda, 2 Acanthocephala, 4 Nematoda, 2 Copepoda et 1 Isopoda. Quatre parasites seulement (Lernanthropus trachuri, Ceratothoa gaudichaudii, Conynosoma australis, Anisakis simplex) sont observés dans les sept localités. A peine douze espèces atteignent une prévalence supérieure à $5 \%$ au moins dans un port. La principale caractéristique de la faune parasitaire est la rareté des helminthes adultes, particulièrement des Digenea, et la prédominance des formes larvaires tant au plan qualitatif que quantitatif. II n'y a pas de preuve de l'existence, le long du gradient latitudinal, de variations dans la communauté parasitaire bien que des larves de Anisakis simplex présentent du nord vers le sud une tendance à l'augmentation de la prévalence et de l'intensité moyenne.

MOTS CLÉS : métazoaires parasites, chinchards, Trachurus murphyi, gradient latitudinal, Chili, Pérou.

munities are known for the Chilean jack mackerel. There is no information on parasites of the Peruvian population of jack mackerel. The aim of this paper is to examine the parasite fauna of this important marine resource, along a latitudinal gradient of more than $30^{\circ}$ in the Pacific coast of South America. Quantitative characteristics of the infectious processes are described and compared along a latitudinal gradient and with published information on parasites of Trachurus.

\section{MATERIALS AND METHODS}

hree thousand and thirty four specimens of Trachurus murphyi were taken seasonally, between November 1993 to August 1994 from two fishing ports in Peru (Paita and Callao) and five fishing ports in Chile (Arica, Iquique, Antofagasta, Coquimbo and Talcahuano) (Table I). Fishes were frozen $\left(-18^{\circ} \mathrm{C}\right)$ at the port within 12 hours after capture and transported to the Laboratory of Parasitology at the Universidad Ricardo Palma, Lima, Perú (fishes from Perú) 


\begin{tabular}{|c|c|c|c|c|c|c|c|c|c|c|c|c|c|c|}
\hline & \multicolumn{2}{|c|}{ PAI } & \multicolumn{2}{|c|}{ CAL } & \multicolumn{2}{|c|}{ ARI } & \multicolumn{2}{|c|}{ IQQ } & \multicolumn{2}{|c|}{ ANT } & \multicolumn{2}{|c|}{ COQ } & \multicolumn{2}{|c|}{ TAL } \\
\hline & $\mathrm{P}$ & I & $\mathrm{P}$ & I & $\mathrm{P}$ & I & $\mathrm{P}$ & I & $\mathrm{P}$ & I & $\mathrm{P}$ & I & $\mathrm{P}$ & I \\
\hline $\mathrm{AXI}^{*}$ & 0.0 & 0.0 & 0.0 & 0.0 & 0.0 & 0.0 & 0.0 & 0.0 & 1.2 & 1.0 & 0.0 & 0.0 & 0.0 & 0.0 \\
\hline PSE* $^{*}$ & 0.0 & 0.0 & 0.0 & 0.0 & 0.0 & 0.0 & 0.0 & 0.0 & 0.5 & 2.5 & 0.0 & 0.0 & 0.0 & 0.0 \\
\hline $\mathrm{CEM}^{*}$ & 15.0 & 1.1 & 0.0 & 0.0 & 0.0 & 0.0 & 0.0 & 0.0 & 0.0 & 0.0 & 0.0 & 0.0 & 0.0 & 0.0 \\
\hline $\mathrm{KUH}^{*}$ & 0.0 & 0.0 & 0.0 & 0.0 & 0.0 & 0.0 & 0.7 & 1.0 & 0.0 & 0.0 & 0.0 & 0.0 & 0.0 & 0.0 \\
\hline CER* & 27.1 & 1.2 & 19.5 & 1.4 & 18.3 & 1.3 & 39.0 & 1.5 & 37.3 & 1.5 & 18.3 & 1.3 & 6.4 & 1.4 \\
\hline $\mathrm{CAL}^{*}$ & 12.3 & 1.1 & 0.2 & 1.0 & 1.9 & 1.0 & 4.8 & 1.1 & 12.3 & 1.2 & 0.4 & 1.0 & 0.0 & 0.0 \\
\hline LER* & 20.9 & 1.1 & 16.2 & 1.5 & 11.1 & 1.1 & 18.6 & 1.1 & 25.0 & 1.3 & 25.6 & 1.3 & 13.1 & 1.2 \\
\hline $\mathrm{COR}^{* *}$ & 4.2 & 2.8 & 12.8 & 2.8 & 1.3 & 1.2 & 12.0 & 4.9 & 17.4 & 2.9 & 4.0 & 2.1 & 1.3 & 2.0 \\
\hline $\mathrm{RAD}^{*}$ & 0.0 & 0.0 & 0.0 & 0.0 & 5.0 & 1.1 & 4.3 & 1.1 & 6.7 & 1.1 & 14.8 & 1.5 & 12.6 & 1.7 \\
\hline ANS $^{* *}$ & 1.5 & 1.2 & 2.1 & 1.2 & 11.3 & 1.2 & 19.0 & 1.7 & 25.2 & 2.1 & 51.7 & 2.0 & 83.5 & 4.6 \\
\hline $\mathrm{ANP}^{* *}$ & 0.0 & 0.0 & 0.0 & 0.0 & 4.4 & 1.3 & 17.0 & 1.7 & 4.9 & 1.4 & 5.5 & 1.2 & 2.3 & 1.2 \\
\hline HYS $^{* *}$ & 0.0 & 0.0 & 0.0 & 0.0 & 0.2 & 1.0 & 0.5 & 1.0 & 0.7 & 1.3 & 1.8 & 1.4 & 27.8 & 1.6 \\
\hline $\mathrm{PTE}^{* *}$ & 0.0 & 0.0 & 0.0 & 0.0 & 0.0 & 0.0 & 0.0 & 0.0 & 0.0 & 0.0 & 0.0 & 0.0 & 0.3 & 1.0 \\
\hline $\mathrm{SCO}^{* *}$ & 0.5 & 1.0 & 0.0 & 0.0 & 3.2 & 1.0 & 8.6 & 1.9 & 9.3 & 3.1 & 0.7 & 1.0 & 6.4 & 2.2 \\
\hline NYB $^{* *}$ & 2.2 & 1.0 & 0.0 & 0.0 & 0.0 & 0.0 & 3.9 & 1.1 & 7.6 & 1.7 & 15.2 & 1.2 & 12.3 & 1.6 \\
\hline TEN** & 2.2 & 1.0 & 0.0 & 0.0 & 1.1 & 1.0 & 1.4 & 1.0 & 0.2 & 1.0 & 0.4 & 1.0 & 1.0 & 1.0 \\
\hline EUT $^{* *}$ & 8.6 & 2.1 & 0.0 & 0.0 & 0.0 & 0.0 & 0.0 & 0.0 & 0.0 & 0.0 & 0.0 & 0.0 & 0.0 & 0.0 \\
\hline $\mathrm{HEP}^{* *}$ & 0.0 & 0.0 & 0.0 & 0.0 & 0.0 & 0.0 & 0.0 & 0.0 & 0.2 & 1.0 & 0.0 & 0.0 & 1.3 & 1.0 \\
\hline HEM $^{*}$ & 0.0 & 0.0 & 0.0 & 0.0 & 0.2 & 2.0 & 0.0 & 0.0 & 0.0 & 0.0 & 0.0 & 0.0 & 0.0 & 0.0 \\
\hline POP* & 0.0 & 0.0 & 0.0 & 0.0 & 0.2 & 1.0 & 0.2 & 1.0 & 0.0 & 0.0 & 0.0 & 0.0 & 0.0 & 0.0 \\
\hline SYN* & 0.0 & 0.0 & 0.0 & 0.0 & 0.0 & 0.0 & 0.2 & 1.0 & 0.0 & 0.0 & 0.0 & 0.0 & 0.0 & 0.0 \\
\hline
\end{tabular}

Parasites: AXI: Axinidae gen sp., PSE: Pseudoanthocotyloides sp., CEM: Cemocotyle aff. trachuri, KUH: Kubnia scombri, CER: Ceratothoa gaudichaudii, CAL: Caligus bonito, LER: Lernanthropus trachuri, COR: Corynosoma australis, RAD: Rhadinorhynchus trachuri, ANS: Anisakis simplex, ANP: Anisakis physeteris, HYS: Hysterothylacium sp., PTE: Pseudoterranova decipiens., SCO: Scolex pleuronectis, NYB: Nybelinia surmenicola, TEN: Tentacularia coryphaenae, EUT: Eutetrarbynchus sp. HEM: Hemiuridae gen. Sp., POP: Pseudopecoelus sp. SYN: Syncoelium filiferum. ${ }^{*}$ : adult stage, ${ }^{* *}$ : larval stage.

Table I. - Prevalence (P) and mean intensity (I) for each metazoa parasite of Trachurus murphyi, from seven ports along the coast of Perú and Chile. Code for ports: $\mathrm{PAI}=$ Paita (Perú), $\mathrm{CAL}=$ Callao $($ Perú $), \mathrm{ARI}=$ Arica $($ Chile $), \mathrm{IQU}=\mathrm{Iquique}(\mathrm{Chile}), \mathrm{ANT}=\mathrm{Antofagasta}$ (Chile), $\mathrm{COQ}=$ Coquimbo $($ Chile $), \mathrm{TAL}=$ Talcahuano $($ Chile $)$.

or Laboratory of Marine Parasitology, at Universidad de Antofagasta (fishes from Chile). Fork length (nearest millimeter) and sex was determined after defrosting.

Parasitological analysis included total necropsy of each fish host. Only metazoan parasites were considered. Each fish was systematically analyzed, first for ectoparasites, including skin, gills and mouth and then for endoparasites. All the viscera, including heart and blood vessels (arterial cone and branchial artery), were analyzed. In order to count parasites, each viscera was separately dissected and washed in running water, all the material retained in a mesh $(0.5 \mathrm{~mm})$ was examined under stereoscope $(20 \times)$. Parasites were fixed, preserved and stained according to traditional techniques (Pritchard \& Kruse, 1982). Ecological descriptors (prevalence, intensity and mean intensity) were calculated according to Bush et al. (1997). Only parasites with prevalence higher than $5 \%$ in at least one locality, were considered in the analysis. Significance of the differences in mean intensity and prevalence along the gradient, were tested with an ANOVA, previous log $(n+1)$ transformation of intensity data and the loglikelihood "G" test, respectively. Association between mean length and mean intensity was explored with the
Pearson product-moment correlation coefficient $r_{p}$ previous $\log (n+1)$ transformation of intensity data. Mean species richness, total richness and number of species in the richest component community (see Guegán \& Kennedy, 1993) for each port, were correlated with mean sea surface temperature, to detect changes in diversity along the latitudinal gradient. SYSTAT (Willkinson, 1990) was used as statistical tool.

\section{RESULTS}

T Wwenty one species of metazoan parasites were obtained. Prevalence, mean intensity, and developmental stage for each parasitic species are given in Table I. Mean size (fork length) of the host differs significantly among localities, as indicated by an ANOVA $\left(\mathrm{F}_{6,3027}=459.46, \mathrm{P}<0.001\right)$, an "a posteriori Tukey test" shows that size differences are not associated with a latitudinal gradient, so, smaller fishes were those from Arica, and the larger those from Paita and Talcahuano, the most northern and southern ports, respectively (Table II). As a rule, the main characteristic of the parasite fauna of jack mackerel for the seven localities is the strong dominance of larval forms. 


\begin{tabular}{|c|c|c|c|c|c|c|c|}
\hline Port & Latitude & $\mathbf{T}$ & $\mathbf{n}$ & Mean size & MSR & TR & RCC \\
\hline PAI & $05^{\circ} 10^{\prime}$ & 18.9 (1) & 406 & 34.0 & 0.95 & 11 & 5 \\
\hline CAL & $12^{\circ} 00^{-}$ & 18.0 & 437 & 26.5 & 0.51 & 5 & 3 \\
\hline ARI & $18^{\circ} 30^{\circ}$ & 17.7 (2) & 476 & 21.2 & 0.56 & 12 & 5 \\
\hline IQU & $21^{\circ} 20^{\prime}$ & $17.0(3)$ & 441 & 26.6 & 1.18 & 14 & 6 \\
\hline ANT & $23^{\circ} 40^{\prime}$ & 17.5 (4) & 432 & 27.2 & 1.46 & 14 & 6 \\
\hline COQ & $29^{\circ} 55^{\prime}$ & 15.9 (5) & 453 & 29.6 & 1.32 & 11 & 5 \\
\hline TAL & $36^{\circ} 40^{\prime}$ & $12.9(6)$ & 389 & 35.0 & 1.61 & 12 & 4 \\
\hline
\end{tabular}

(1) Mean of 1939-1969, (2) mean of 1951-1995, (3) mean of 1983-1997, (4) mean of 1946-1995, (5) mean of 1979-1997, (6) mean of 19491995 .

Table II. - Ports, latitude, mean sea surface temperature(T), sample size (n), mean size (fork length in $\mathrm{cm}$ ) of fishes, Mean Species richness (MSR), Total Richness (TR) and number of species in the richest component community (RCC). Temperature from Peruvian ports according to Zuta and Urquizo (1972). Temperature from Chilean Ports provided by CENDOC-SHOA (Centro Nacional de Datos Oceanograficos-Servicio Hidrográfico y Oceanográfico de la Armada). Code for ports as in Table I.

Ectoparasites (Monogenea, Copepoda and Isopoda) account for $33.3 \%$ of the metazoan parasitic species, and endoparasites reaches $69.5 \%$ of the total number of individuals (total number of parasitic individuals was 6,426). Larval helminthes were $94 \%$ of the endoparasites and adult endohelminth account just $0.41 \%$ of the parasites. This pattern occurs in all localities, except Callao, were ectoparasites are dominant. Richest parasite fauna (Table II) was found in Antofagasta and Iquique (14 species), the lower in Callao (five species). Mean number of parasitic species and mean number of individuals differ significantly along the gradient (ANOVA $\mathrm{F}_{6,3027}=124.85, \mathrm{p}<0.0001$ for species, $\mathrm{F}_{6,3027}=186.1, \mathrm{p}<0.001$ for individuals), the " a posterior $i$ Tukey test" shows that differences are not related to the north-south gradient. In a similar way, no correlation was detected between mean size of fishes (for each port) and mean number of parasitic species and mean number of individuals $(\mathrm{r}=0.59, \mathrm{P}=0.19, \mathrm{df}=5$; $\mathrm{r}=0.61, \mathrm{P}=0.14$, $\mathrm{df}=5$; respectively).

Only four species are common to the seven localities: the copepod Lernanthropus trachuri a species proper of fishes of the genus Trachurus, the isopod Ceratothoa gaudichaudii found in pelagic fishes from this zone and larval stages of Corynosoma australis (Acanthocephala) and $A$. simplex (Nematoda) that are common parasites of marine fishes.

Trends of mean intensity and prevalence of infection, for those parasites with prevalence higher than $5 \%$ in at least one locality along the latitudinal gradient, are shown in Figure 1 and Figure 2. Graphically appears that just the Nematoda Anisakis simplex and Hysterothylacium sp. and the adult Acanthocephala Rhadinorbynchus trachuri show trends in a latitudinal gradient, increasing both prevalence and mean intensity from north to south, but statistical analysis shows that differences are significant only for Anisakis simplex, in both prevalence and mean intensity. Diversity, expressed as mean species richness, total richness and richest component community are not associated $(r=0.67, P=0.09 ; r=0.234, P=0.24 ; r=0.21$, $\mathrm{P}=0.65$, respectively. $\mathrm{df}=5$ ) with mean sea surface temperature for each port.

\section{DISCUSSION}

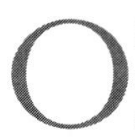
$\mathrm{f}$ the listed species in Table I, the Monogeneans, the larval Eucestode Eutetrarbynchus sp. and the Digenea Syncoelium filiferum are registered for the first time in this fish host, also they represent new geographical records. The Monogeneans Pseudanthocotyloides sp. and Kubnia scombri are considered as accidental parasites. Pseudanthocotyloides is a genus proper of Engraulids and Clupeids and Kubnia scombri is a well known parasite of horse mackerel of the genus Scomber (Mamaev, 1982). $K$. scombri and K. sprostonae are parasites of the horse mackerel Scomber japonicus peruanus in peruvian waters (Luque et al., 1991). Also they have been found in mackerel from Antofagasta, Chile (unpublished information). At least six species of monogeneans are known as parasites of fishes of the genus Trachurus (Llewellyn 1962, Gaevskaya \& Kovaleva, 1980), but only one of them (Cemocotyle aff. trachuri) has been found in the northest locality of Peru (Paita). Absence of C. aff. trachuri in Chile (in all localities) and in Callao (central Peru) suggests the presence of two independent stocks of jack mackerel. Furthermore, absence of monogenean proper of jack mackerel of the genus Trachurus in the Pacific coast of South America has been considered as a consequence of a long isolation period from its congeners (Oliva, 1994).

Published information about metazoan parasites of the Chilean jack mackerel are consistent in detecting a poor parasite fauna. George-Nascimento \& Arancibia (1992) found 14 species of metazoan parasites in a sample of 1,383 specimens of jack mackerel from 

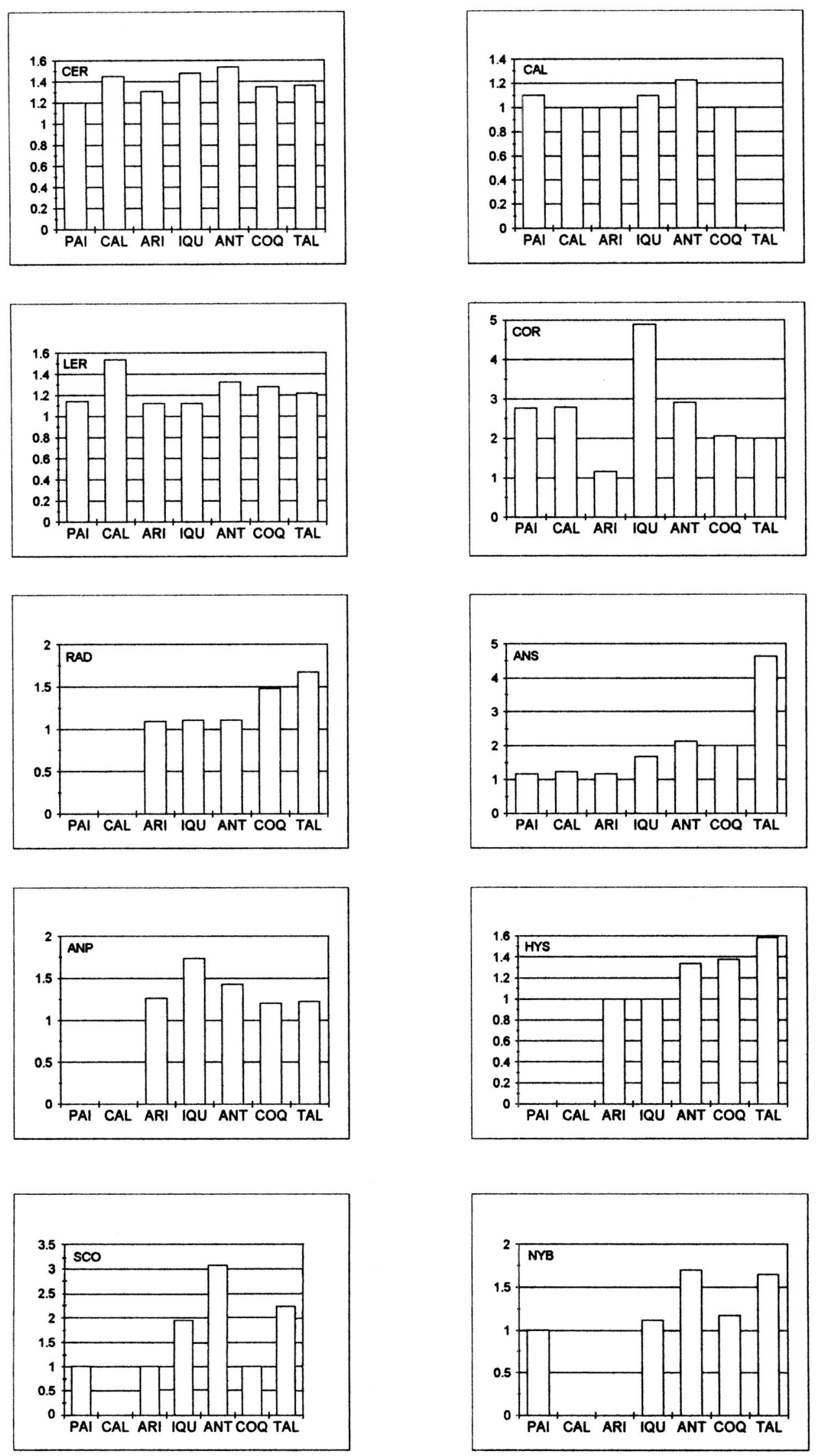

Fig. 1. - Trends in mean intensity, for species with prevalence higher than $5 \%$ in at least one port, along the latitudinal gradient. Species and port code as in Table I. 

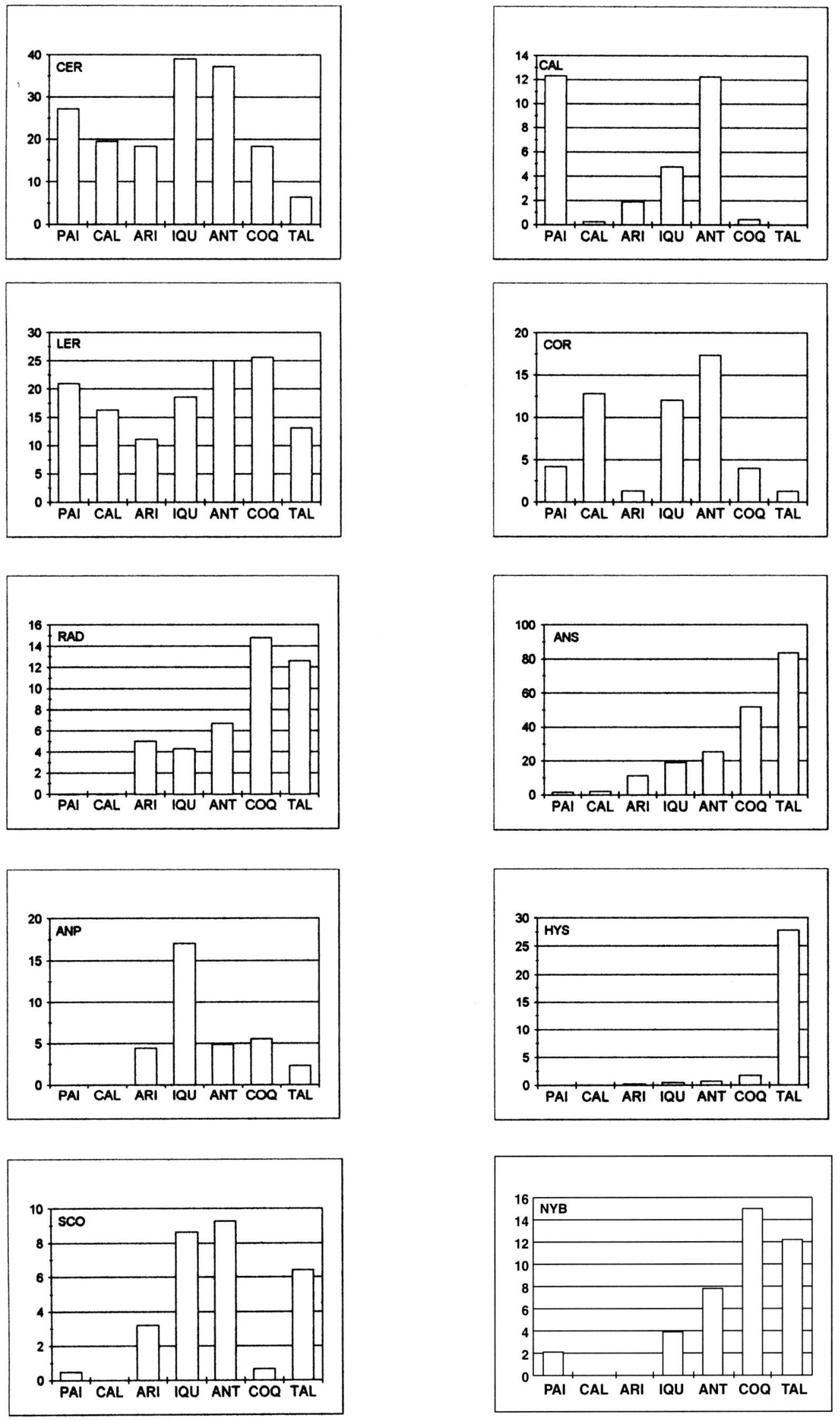

Fig. 2. - Trends in prevalence of infection, for species with prevalence higher than $5 \%$ in at least one port, along the latitudinal gradient. Species and port code as in Table I. 
Iquique, Talcahuano and the oceanic fisheries. Oliva (1994) was able to detect nine species of metazoan parasites in a sample of 78 jack mackerel from Antofagasta. The mean number of parasite individuals per host found by George-Nascimento \& Arancibia (1992) and Oliva (1994) (1.73 and 1.65, respectively) is less than the now reported (2.11).

A characteristic of marine fishes from Chile and Perú is the sparse of their parasite fauna (metazoa), when compared with related fishes from different geographical areas; this phenomena has been documented for the flatfish Paralichthys adpersus by Oliva et al. (1996), the rock fish Sebastes capensis by Gonzalez \& Acuña (1998) and the sciaenids Menticirrbus opbicephalus, Stellifer minor, Paralonchurus peruanus, Sciaena deliciosa and Sciaena fasciata by Oliva \& Luque (1998). In the main, differences are related to trophically transmitted parasites, specifically digeneans. This picture applies also to the jack mackerel. Both, George-Nascimento \& Arancibia (1992) and Oliva (1994) were able to found just one species of Digenea, an unidentified opecoelid (Pseudopecoelus sp.) in jack mackerel from Chile. In this study I found three digenean species: Pseudopecoelus sp., an unidentified juvenile Hemiurid and Syncoelium filiferum. Pseudopecoelus sp. is a rare species, present only in two ports, with low values of prevalence that agree with those reported by GeorgeNascimento \& Arancibia (1992), but are significantly lower than those indicated by Oliva (1994). The Hemiurid and S. filiferum must be considered as accidental parasites: both species were obtained just once: the hemiurid from Arica (Chile) and S. filiferum also from a Chilean port, Iquique. In a similar way, Piasecki (1982) was unable to found digeneans in a sample of 87 cape mackerel Trachurus t. capensis. But in contrast, jack mackerel from the Atlantic coast of Africa and Europe are parasitized by numerous species of Digenea, as showed by extensive surveys done by Gaevskaya \& Kovaleva $(1980,1982)$ who were able to find 17 and 21 species of digenean in the Atlantic mackerel Trachurus trachurus. Other endohelminth parasites show a similar pattern, for instance, adult Acanthocephala are poorly represented in jack mackerel from Chile and Peru, Rhadinorbynchus trachuri was found by George-Nascimento \& Arancibia (1992) with low prevalence $(2.0 \%)$, in this research this worm was found only in the Chilean port, with prevalence ranging from $4.3 \%$ to $14.8 \%$, suggesting a latitudinal gradient with higher prevalence in the south, also main values of intensity are associated to the south. Cystacanth of Corynosoma australis were found along the seven ports, but Bolbosoma turbitella, a larval acanthocephala recorded by George-Nascimento \& Arancibia (1992) was not found. Observed Eucestoda were all larval forms of Tetraphyllidea and Try- panorhyncha, suggesting that jack mackerel is a frequent item of sharks' diet. Presence of Eutetrarbynchus sp. in Paita may provide more parasitological evidence for existence of two independent stocks.

Scott (1982) claims that lower helminth richness can be explained as a function of the sampled geographical area, because of the relationship between species richness and latitudinal range of the host. This must be true for those studies that imply samples for only one geographical locality independent of the host latitudinal range (i.e. Oliva, 1994; Gonzalez \& Acuña, 1998; Oliva \& Luque, 1998). In this paper, is demonstrated that the poor fauna of adult intestinal endohelminth parasites of the jack mackerel remains along more than $30^{\circ}$ of latitudinal gradient. Moreover, diversity, expressed as mean species richness, total richness and richest component community does not follow a latitudinal gradient, when those communitary descriptors are associated to temperature. Latitudinal effect on diversity is related with changes in available energy, that can be measured as temperature (Rohde, 1992).

The data set of the parasite fauna of marine fishes from this geographical area, the Peruvian Faunistic Province (PFP), is yet scarce. PFP includes the central and southern Peruvian coast and the northern and central Chilean coast, with a southern boundary ca. $30^{\circ} \mathrm{S}$ (Brattström \& Johanssen, 1983; Mac Lean, 1984) and is characterized by oceanographic processes such as upwelling and the El Niño Southern Oscillation (see Oliva \& Luque, 1998).

As pointed above, parasite community, specifically digeneans, of the jack mackerel follows a similar pattern with other coastal marine fishes from the PFP. Oliva et al. (1996) gave a list of 13 host species and the number of digeneans harbored, the recent finding of Gonzalez \& Acuña (1998) reinforced this picture. Sample size has been considered as a factor that can affect communitary descriptors, such as prevalence, intensity and diversity (Gregory \& Blackburn, 1991). The sample size, along the seven ports was high and similar, so the well known effect of sample size and sample effort (Guegán \& Kennedy, 1996) is excluded. The importance of benthic and plantonic organisms on the transmission of parasites has been discussed by Marcogliesse (1995) and Jackson et al. (1997). A low diversity of the pelagic and benthic systems has been proposed as an explanation for the poor parasite fauna of fishes from this area (Oliva \& Luque, 1998). Unpublished data of Kong et al. demonstrated that the diet of the jack mackerel, from Chile, includes at least 20 items, but the anchovy Engraulis ringens explains more than $80 \%$ of the index of relative importance, the second most import food item are Euphausids. Parasites of $E$. ringens have been studied by Riffo (1990) nearby Talcahuano, but the author was unable 
to detect either larval, or adult digeneans. Also, features of E. ringens parasites match with those of the parasite fauna (metazoa) from the FPP.

Diversity of trophically transmitted parasites, such as digeneans, might reflect the diversity of the diet (Cribb et al., 1994). Thus a combination of two factors: a highly specialized diet and a low diversity in the pelagic and benthic community, can explain the scarce fauna of trophically transmitted parasites. More studies on diet and structure of benthic and pelagic communities can reinforce or reject this hypothesis. Additionally, the extenuation of the continental shelf must be considered as a potential factor that can explain the sparse fauna of digenean. Digenea use molluscs as first intermediate host, and the presence of a narrow continental shelf implies a "relative limited habitat" available for benthic molluscs. This hypothesis can be tested by association between richness of digenean parasites in marine fishes and width of the continental shelf. In Chile such shelf is rather narrow, whose slope $(200 \mathrm{~m}$ isobath) can be found within $20 \mathrm{~nm}$ from the shoreline (at least between Talcahuano and Arica). Although the continental shelf is wider in Perú (ca. $40 \mathrm{~nm}$ off Callao and $25 \mathrm{~nm}$ off Paita), digenean parasites of Trachurus murphyi do not increase northward. Certainly, to test this hypothesis a more robust data set would be needed.

\section{ACKNOWLEDGEMENTS}

I am grateful to CENDOC-SHOA (Centro Nacional de Datos Ocenográficos-Servicio Hidrogáfico y Oceanográfico de la Armada de Chile), for temperature data from Chilean Ports. R. Escribano helped improving English usage and L. Ortlieb translated the Abstract into French. Miguel A. Perea (IMARPE-PERU) provided valuable information about continental shelf in Perú. Partial results of the Project "Estudio Biológico Pesquero del Jurel en las regiones I y II (Chile)" Fisheries Research Fund-Chile.

\section{REFERENCES}

Brattström H. \& Johanssen A. Ecological and regional biogeography of the marine benthic fauna of Chile. Report No 49 of the "Lund University Chile Expedition 1948-1949". Sarsia, 1983, 68, 289-339.

Bush A.O., Lafferty K.D., Lotz J.M. \& Shostak A.W. Parasitology meets Ecology on its own terms: Margolis et al. revisited. Journal of Parasitology, 1997, 83 (4), 575-583.

Cribb T.H., Bray R.A., Barker S.C., Adlard R.D. \& Anderson G.R. Ecology and diversity of digenean trematodes of reef and inshore fishes of Queensland. International Journal of Parasitology, 1994, 24, 851-860.
Gaevskaya A.V. \& Kovaleva A.A. Similarities and differences in the parasite fauna of two subspecies of Trachurus from the Atlantic Ocean. Biologicheskii Nauki, 1980, 6, 52-56 (in Russian).

Gaevskaya A.V. \& Kovaleva A.A. The trematode fauna of Atlantic Trachurus and its special features. Gidrobiologicheskii Zhurnal, 1982, 18, 60-65 (in Russian).

George-Nascimento M \&. Arancibia H. Stocks ecologicos del jurel (Trachurus symmetricus murphyi Nichols) en tres zonas de pesca frente a Chile, detectados mediante comparación de su fauna parasitaria y morfometría. Revista Chilena de Historia Natural, 1992, 65, 453-470.

Gonzalez M.T. \& Acuña E. Metazoan parasites of the red rockfish Sebastes capensis off northern Chile. Journal of Parasitology, 1998, 84 (4), 783-788.

Gregory R.D. \& Blackburn T.M. Parasite prevalence and host sample size. Parasitology Today, 1991, 7, 316-318.

GuEGÁN J.F. \& KENNEDY C.R. Maximum local helminth parasite community richness in British freshwater fish: a test of the colonization time hypothesis. Parasitology, 1993, 106, 91-100.

Guegán J.F. \& Kennedy C.R. Parasite richness/sampling effort/host range: the fancy three piece jigsaw puzzle. Parasitology Today, 1996, 12, 367-369.

Jackson C.J., Marcogliese D.J. \& Burt M.D.B. Role of hyperbenthic crustacea in the transmission of marine helminth parasites. Canadian Journal of Fisheries and Aquatic Sciences, 1997, 54, 815-820.

LLEWELLYN J. The life histories and population dynamics of monogenean gill parasites of Trachurus trachurus. Journal marine Biological Association United Kingdom, 1962, 42, 587-600.

Luque J.L., Iannacone J. \& Farfán C. Parásitos de peces oseos marinos en el Perú: Lista de especies conocidas. Boletín de Lima (Perú), 1991, 74, 17-28.

Mamaev Y.I. Notes on the systematics of Mazocraeid monogeneans with a redescription of some poorly studied taxa. Helminthologia, 1982, 19, 25-39.

MCLEan J.H. Systematics of Fissurella in the Peruvian and Magellanic faunal provinces (Gastropoda: Prosobranchia). Natural History Museum of Los Angeles County, Contributions in Science, 1984, 354, 1-70.

Marcogliesse D.J. The role of zooplancton in the transmission of helminth parasites to fish. Reviews in Fish Biology and Fisheries, 1995, 5, 336-371.

OuIVA M.E. Parasites of the Chilean jack mackerel Trachurus symmetricus murphyi (Pisces: Carangidae). Memorias Instituto Oswaldo Cruz, 1994, 89, 363-364.

Oliva M.E., Castro R.E. \& Burgos R. Parasites of the flat fish Paralichthys adspersus (Steindachner, 1867) (Pleuronectiformes) from northern Chile. Memorias Instituto Oswaldo Cruz, 1996, 91, 301-306.

OLIVA M.E. \& LuQuE J.L. Metazoan parasite infracommunities in five sciaenids from the central Peruvian coast. Memorias Instituto Oswaldo Cruz ,1998, 93, 175-180.

PIASECKI W. Parasitofauna of cape horse mackerel Trachurus trachurus capensis Castelnau, 1861. Acta Ichthyologica et Piscatoria, 1982, 12, 43-56. 
Pritchard M.A. \& Kruse G.O. The collection and Preservation of animal parasites. University of Nebraska Press, 1982, 141 pp.

RIFFO R. Primer registro parasitológico en Strangomera benticki (Norman, 1936) y Engraulis ringens Jennys, 1842 (Pisces: Clupeiformes) para la costa de Chile. Medio Ambiente (Chile) 1990, 11 (1), 59-64.

ROHDE K. Latitudinal gradients in species diversity: the search for the primary cause. Oikos, 1992, 65, 514-527.

ScotT J.S. Digenean parasite communities in flatfishes of the Scotland shelf and Southern Gulf of Saint Lawrence. Canadian Journal of Zoology, 1982, 60, 2804-2811.

SERNAPESCA. Anuario estadistico de Pesca. Ministerio de Economía Fomento y Reconstruccion-Chile, 1997, 224 pp.

WILKINSON L. SYSTAT: The system for statistics. Evanston, IL: SYSTAT, Inc Wilkinson, 1990.

Zuta S. \& URQuizo W. Temperatura promedio de la superficie del mar frente a la costa Peruana. Periodo 1928-1969, Boletín Instituto del Mar del Perí, 1972, 2 (8), 459-520.

Reçu le 29 janvier 1999

Accepté le 22 juin 1999 